\title{
PERCEPÇÃO DOS PAIS DE GESTANTES ADOLESCENTES SOBRE A EDUCAÇÃO SEXUAL
}

\author{
PERCEPTION OF PARENTS OF PREGNANT ADOLESCENTS ON SEX EDUCATION
}

\section{Janayna Barros Reina Villas Boas ${ }^{\mathrm{a}^{*}}$, Maria Fernanda Pereira Gomes ${ }^{\mathrm{b}^{*}}$, Kesley de Oliveira Reticena $^{c^{*}}$, Verusca Kelly Capellini ${ }^{\mathrm{d}^{* *}}$, Lislaine Aparecida Fracolli ${ }^{* * *}$}

\author{
ajanaynabarros@yahoo.com.br, bmferpg@usp.br, ckesleyreticena@hotmail.com, dveruscakelly@hotmail.com, elislaine@usp.br \\ *Universidade Paulista - Assis (SP), Brasil \\ **Fundação Educacional do Município de Assis - Assis (SP), Brasil \\ ${ }^{* * *}$ Escola de Enfermagem da Universidade de São Paulo - São Paulo (SP), Brasil
}

Data de recebimento do artigo: 27/04/2017

Data de aceite do artigo: 06/07/2017

\section{RESUMO}

Objetivo: Apreender a percepção dos pais acerca da gestação na adolescência e da educação sexual oferecida no contexto escolar e das unidades básicas de saúde (UBS). Métodos: Abordagem qualitativa descritiva exploratória. O estudo foi realizado em domicílios de familiares de gestantes adolescentes usuárias das UBS do município de Assis (SP). Participaram da pesquisa oito pais de gestantes adolescentes entre doze e dezenove anos. Os dados foram colhidos no período de julho a agosto de 2016, por meio de roteiro semiestruturado. O tratamento dos dados foi baseado na técnica de análise de conteúdo, em que as entrevistas foram submetidas a três processos: ordenação, classificação e análise final. Desses processos emergiram as seguintes temáticas: conhecimento do uso dos métodos contraceptivos existentes e concordância da educação sexual dos filhos adolescentes; influência da educação na prática sexual precoce e ocorrência de gravidez; impactos da gestação precoce; e posição quanto à intervençáo governamental na educação sexual adolescente. Resultados: Foi possível observar que os pais não se contrapóem totalmente às açóes governamentais, entretanto, reivindicam o pátrio poder quanto às tomadas de decisóes relacionadas às vidas dos filhos. Conclusáo: A problemática social gerada pelas gestaçóes precoces deve ser abordada pelas instituições governamentais, mas não só voltada ao público adolescente como também aos pais e à família.

Palavras-chave: Gravidez na adolescência; educação sexual; relações familiares.

\section{ABSTRACT}

Objective: To identify the perception of parents about adolescent pregnancy and the sex education offered in schools and basic health units. Methods: Exploratory descriptive qualitative approach. The study was performed at the homes of relatives of pregnant adolescents assisted by the basic health units of the city of Assis (São Paulo, Brazil). Eight parents of pregnant adolescents aged 12-19 years participated in the study. Data collection occurred from July to August 2016 through a semi-structured questionnaire. Data treatment was based in content analysis technique, in which the interviews were submitted to three processes: sorting, classification, and final analysis. From this process, the following topics emerged: knowledge on use of existing contraceptive methods and agreement to the sex education of the adolescents; influence of education on early sex practice and occurrence of pregnancy; impacts of early pregnancy; and parents' position regarding government's intervention in adolescent sex education. Results: It was possible to observe that the parents do not totally oppose the government actions; nevertheless, they claim the parental responsibility in the decision-making related to their children's lives. Conclusion: Social problems generated by early pregnancies must be addressed by government institutions, not only dedicated to the adolescent public, but also including their parents and family.

Keywords: Pregnancy in adolescence; sex education; family relations. 


\section{Introdução}

A prática de atividade sexual durante a adolescência pode levar à gravidez náo planejada que, por sua vez, pode trazer sérias complicaçóes maternais e fetais ${ }^{1}$.

De acordo com o Ministério da Saúde (MS), através dos indicadores sociodemográficos e de saúde no Brasil nota-se que, do total de mulheres de quinze a dezessete anos (5,1 milhóes), 311 mil tiveram filhos no mesmo ano, o que corresponde ao percentual de $6 \%$ dessa faixa etária ${ }^{2}$. Ainda, conforme dados do Sistema de Informação de Nascidos Vivos (Sinasc) do MS, em 2014, o percentual de meninas com idade entre dez e dezenove anos que já tiveram filhos foi de aproximadamente $19 \%$, correspondendo a 562.608 gestações; em 2009 o índice de gestação precoce era mais baixo, entretanto a taxa de meninas de até quinze anos que já tiveram filhos vem aumentando ${ }^{3}$.

Esses dados são bastante expressivos, levando-se em consideração todo o quadro que as gestaçóes precoces acarretam para a adolescente, família e sociedade. Dentre as principais complicaçóes neonatais encontradas estão a prematuridade, o baixo ou muito baixo peso ao nascer e a mortalidade perinatal. Como principais complicaçóes maternas estão a doença hipertensiva específica da gestaçáo, o abortamento, a infecçáo urinária e a ruptura prematura das membranas ovulares ${ }^{1}$.

O MS, junto com demais órgãos, como o Ministério da Educação, vem trabalhando em diversas políticas, estratégias e açóes voltadas à população adolescente, pois percebe-se claramente que a educação desse público é a melhor ferramenta não só para prevenção da gestação precoce, como em todos os âmbitos da saúde ${ }^{4}$.

Obteve-se, através de dados, estatísticas, estudos e avaliações, várias conquistas, como: o Estatuto da Criança e do Adolescente (ECA), lei no 8.069, sancionada em 13 de julho de 1990, que dispóe sobre a proteção integral, os direitos e deveres da criança e do adolescente ; a Política Nacional de Atenção Integral à Saúde de Adolescentes em Conflito com a Lei, iniciada em 2004, preocupada com o bem-estar biopsicossocial desse grupo $^{6}$; as Diretrizes Nacionais para a Atenção Integral à Saúde de Adolescentes e Jovens na Promoção, Proteção e Recuperação da Saúde, lançadas em $2010^{4}$; o projeto Saúde e Prevenção nas Escolas, realizado junto com o Ministério da Educaçáo, com apoio da Organização das Naçóes Unidas para a Educação, a Ciência e a Cultura (Unesco) e do Fundo das Nações Unidas para a Infância (Unicef), lançado em junho de 2007, buscando integrar promoção da saúde, educação e prevenção à realidade de alunos do ensino fundamental e médio ${ }^{7}$, entre outras muitas ações já lançadas e implementadas, ações essas que resultaram na diminuiçáo considerável dos casos de gestação precoce e seus agravos.
Embora se entenda o papel da educação em todos os setores da vida, quando se trata de educação sexual e preventiva na adolescência, surgem barreiras que acabam interferindo diretamente na aplicação das açóes voltadas a esta temática, podendo ocorrer por diversos motivos, como: tabu, tradição, religião, crenças, opiniōes e outros fatores 5 .

Dentro desse tema polêmico, pode-se ver a recusa de muitos pais à discussão sobre sexo na adolescência (ato) e educação sexual adolescente (prevenção) ${ }^{6}$.

Dessa forma, este trabalho tem relevância, visto que a gestação precoce é um problema de saúde pública e traz consequências de curto, médio e longo prazo, podendo interferir de maneira abrangente na vida de adolescentes e suas famílias. Ademais, é necessário conhecer o ponto de vista dos pais das adolescentes grávidas em relação aos recursos educacionais sobre saúde sexual ofertados pelos órgãos competentes.

Assim, este trabalho tem o objetivo de apreender a percepção dos pais acerca da gestação na adolescência a partir da educaçáo sexual oferecida no contexto da escola e da UBS.

\section{Método}

Adotou-se a abordagem qualitativa, descritiva e exploratória. O estudo foi realizado em domicílios de familiares de gestantes adolescentes usuárias das UBS do município de Assis/SP.

Segundo dados do $\mathrm{IBGE}^{8}$, o município de Assis possui 95.144 habitantes; 14.155 deles têm entre dez e dezenove anos e 3.549 são alunos matriculados no ensino médio ${ }^{8}$. De acordo com o Departamento de Informática do Sistema Único de Saúde (DataSUS), em 2013, o município teve 181 nascidos vivos de mães entre dez e dezenove anos?

Participaram da pesquisa pais que atenderam ao critério de inclusão de ter filhas gestantes adolescentes entre doze e dezenove anos, que aceitaram colaborar com o estudo após a apresentação dos objetivos e mediante assinatura do Termo de Consentimento Livre e Esclarecido (TCLE). Foram excluídos os pais que não concordaram em participar da pesquisa.

Houve a seleção de oito genitores (mães e pais) que aceitaram participar da pesquisa com a ajuda da equipe que trabalha na Saúde da Família do município de Assis/ SP. Após a primeira seleçấo, foi realizada visita domiciliar para coleta de dados. A visita foi agendada em horário e dia oportuno para o pai ou a mãe participante, por meio de contato telefônico prévio e abordagem na UBS.

Os dados foram colhidos no período de julho a agosto de 2016, por meio de roteiro de pesquisa 
semiestruturado, o qual abrange questôes sobre características sociodemográficas, educação sexual e gestação na adolescência.

Para análise, as entrevistas foram transcritas na íntegra e, depois, passaram pelas três etapas do processo da análise de conteúdo da modalidade temática, sendo elas: ordenação, classificação e análise final ${ }^{10}$. Desse processo emergiram as seguintes temáticas: conhecimento do uso dos métodos contraceptivos existentes e concordância da educação sexual dos filhos adolescentes; influência da educação sexual na prática precoce e ocorrência de gravidez; impactos da gestaçáo precoce; e posiçáo quanto à intervenção governamental na educação sexual adolescente.

Para assegurar o anonimato, os depoentes foram denominados com os nomes de planetas pertencentes à galáxia Via Láctea.

Esta pesquisa obteve o $\mathrm{n}^{\mathrm{o}}$ de Certificado de Apresentação para Apreciação Ética (CAAE) 54257316.6.0000.5512 e no de parecer 1.500.884 do Comitê de Ética e Pesquisa.

\section{Resultados e discussão}

Inicialmente, tem-se a descrição sociodemográfica dos pais participantes para, em seguida, serem apresentadas as categorias temáticas que emergiram do estudo.

\section{Descrição sociodemográfica dos pais partici- pantes}

Somente um dos entrevistados era do gênero masculino, as idades variaram entre 35 e 45 anos, sendo que três participantes tinham entre trinta e quarenta anos, e cinco entre quarenta e cinquenta anos. Quanto ao estado civil, havia uma pessoa solteira, duas casadas, duas divorciadas e três viviam em união estável. Quatro participantes possuíam ensino fundamental incompleto; dois o ensino médio incompleto e dois possuíam ensino médio completo. Metade dos entrevistados trabalhava fora de casa e metade era do lar. Em relaçấo à renda, três participantes declararam receber até um salário-mínimo, e cinco tinham renda de até dois salários. Nas residências com maior número de moradores também foram encontradas as menores faixas salariais (um salário-mínimo): em uma das residências visitadas havia dez moradores vivendo com a renda de um provedor. $\mathrm{O}$ número de moradores nas residências variou de três a dez pessoas. Uma característica importante observada nas residências foi que algumas famílias moravam no mesmo lote, em casas separadas, porém com uma única renda. Os pais entrevistados tinham de dois a seis filhos.
Todas as famílias e residências visitadas são cobertas pela Atenção Primária à Saúde, sendo que três famílias são acompanhadas pela Estratégia de Saúde da Família (ESF) e recebem visitas periódicas de agentes comunitários de saúde, e cinco famílias são acompanhadas nas UBS e somente recebem auxílio de saúde se o buscarem na unidade. Ainda, ressalta-se que dentre as filhas dos oito entrevistados apenas quatro jovens grávidas estavam frequentando a escola.

\section{Informações sobre métodos contraceptivos e educação sexual dos adolescentes}

Todos os pais acreditavam conhecer os métodos contraceptivos, como expresso nos relatos de cada um deles:

Sim, camisinha, pilula, injeção. (Júpiter, quarenta anos)

Sim, todos eu acho, mas não tenho certeza, esses aí que a gente mais vê eu sei sim, camisinha, pilula, injeção. (Saturno, 45 anos)

Sim, todos, comprimido, camisinha e injeção. (Vênus, 37 anos)

A partir dos relatos é possível verificar que os pais acreditam conhecer todos os métodos contraceptivos. Pode-se averiguar, porém, que não os conhecem realmente, pois a maioria dos entrevistados aponta apenas os métodos mais divulgados, como anticoncepcional oral, camisinha e anticoncepcional injetável. Alguns disseram estar a par de todos os métodos, entretanto, se recusaram a citar os que conheciam.

$\mathrm{Na}$ pesquisa realizada no município de fortaleza com sete familiares de gestantes adolescentes, identificou-se que a gestação precoce decorre da fragilidade do comprometimento educador dos pais, em consequência de eles próprios não disporem de informações suficientes ou ficarem constrangidos em falar sobre sexo com seus filhos; do insuficiente preparo dos profissionais que trabalham com adolescentes ao abordar assuntos como sexualidade e prevençáo da gravidez; e da imaturidade e inexperiência dos adolescentes para se apoderarem dos conhecimentos necessários a fim de fazer uso correto dos métodos contraceptivos ${ }^{11-13}$.

No momento da coleta dos dados, observou-se o surgimento de um possível efeito Hawthorne, caracterizado pela expressiva mudança de comportamento na linguagem corporal, nas falas e reaçóes dos entrevistados, principalmente nas relações mãe e filha.

A respeito da educaçáo sexual ofertada aos filhos pela escola e UBS, os pais concordam: 
Sim, pra prevenir melhor né, sem saber eles fazem, acho que pelo menos alguém vai seguir os conselhos né. (Netuno, quarenta anos)

Sim, porque a molecada de hoje está começando a atividade sexual deles mais cedo. (Marte, 35 anos)

Sim, porque talvez outra pessoa falando mais e mais na cabę̧a ajude, a gente fala, mas eles parece que num ouve, é aquele negócio santo de casa num faz milagre! Quem sabe alguém de fora falando eles dão ouvido. (Vênus, 45 anos)

Pode-se observar que todos os participantes relataram concordar com a educação sexual dos filhos, porém essa foi uma das questôes em que se evidenciou o surgimento do efeito Hawthorne ${ }^{14}$. Em sua maioria, as adolescentes presentes demonstravam discordância através de expressóes e algumas até mesmo contestavam a opiniáo dada pelo genitor, manifestando assim uma mudança de comportamento durante a entrevista. Esse fato ocorreu em mais de um questionamento.

\section{Influência da educação sexual na prática precoce e ocorrência de gravidez}

No âmbito dos relacionamentos e do diálogo intrafamiliar, no que diz respeito à comunicação de teor educativo quanto a sexo, gravidez e doenças sexualmente transmissíveis (DST), os pais responderam que conversavam com suas filhas sobre o assunto antes da gravidez. Surgiu também o efeito Hawthorne, identificado através de comportamentos, expressões não verbais e negação por parte das gestantes quanto à afirmação dos pais, denotando, assim, uma postura diferente quanto à realidade.

$\mathrm{Na}$ pesquisa realizada no alojamento conjunto do Hospital Universitário da Universidade de São Paulo/ SP com dez mães de adolescentes grávidas, as entrevistadas afirmaram que orientaram suas filhas em relação à sexualidade na adolescência, ao uso de preservativo para evitar doenças e gravidez, e à perda da juventude, com início precoce da vida adulta ${ }^{15}$.

Em contrapartida, muitas pesquisas têm mostrado que a família encontra dificuldades no cuidado e apoio à gestação de uma adolescente. Entre as dificuldades encontradas destaca-se a comunicação, ou seja, a inabilidade para conversar sobre sexualidade com filhas e filhos ${ }^{16-18}$.

Os entrevistados relataram influência do diálogo sobre sexo na prática precoce pelos adolescentes:

Eu acho que previne se usar a experiência pro lado bom, se eles usarem o que aprenderem realmente preveniria, mas já viu adolescente ter juizo? Entra por um ouvido e sai pelo outro, eles só acreditam depois que já é tarde. (Terra, 37 anos)

Previne, mas se eles faz ou deixa de fazer, faz esclarecido, apesar que eles sabem é mais do que a gente. (Júpiter, 37 anos)

Menina, pra ser sincera, eu acho que näo previne nada näo, eles fazem do mesmo jeito, e não influencia em nada porque quando a gente ou a escola as meninas do postinho vão falar pra eles, eles já tâo é fazendo faz é tempo. (Netuno, quarenta anos)

Quanto aos conhecimentos das açóes de saúde e educaçáo realizadas pelo governo federal, todos os pais entrevistados disseram saber sobre as açōes existentes atualmente para a prevenção de gravidez na adolescência. Alguns pais se mostraram satisfeitos com essas ações, outros acreditam que não há muito a ser feito, e alguns estão insatisfeitos, conforme se vê pelos depoimentos:

Sim, eu acho que está bom, não sei se tem como melhorar essas coisas, isso é uma coisa dificil porque adolescente é dificil. (Vênus, 45 anos)

Eu creio que o governo acha mais que a educação vem dos pais, não tem muito o que fazer, o que o governo pode melhorar eu não sei! (Marte, 35 anos)

Poderia mudar sim, eu mesma não queria ter tanto filho, mas até hoje eu não consegui operar, é muito dificil conseguir cirurgia, agora eu quero que a minha menina mais velha "opera", mas eles dizem que não pode porque ela é muito nova, mas ela já está indo pro terceiro, se ela for esperar pra operar com a idade que eles querem ela já vai estar com dez filhos (risos); eu ainda posso ter mais; a única coisa boa é que aí o bolsa família aumenta né? (Júpiter, 37 anos)

Os relatos analisados demonstraram que os pais acreditam que os adolescentes não utilizam as ferramentas existentes. Além disso, manifestam insatisfação com as açôes atuais, não só aquelas voltadas para a prevençáo à gestação precoce, como também as de planejamento familiar em geral. Os pais acreditam que a educação advinda de casa é mais importante e eficaz em comparação às açóes governamentais.

Numa pesquisa realizada com 22 gestantes adolescentes no município de São Paulo/SP, 40\% afirmaram que não aprenderam nada com os pais sobre sexo e gravidez ${ }^{19}$.

Quanto à melhor idade para iniciar os conhecimentos sobre educação sexual, obteve-se uma variedade de respostas: 
Uns catorze anos, não tem que falar antes, esse é o problema, criança tem que brincar, e não saber sobre sexo, as crianças estão entrando cedo demais nessa vida, a gente tem que poupar, levar elas de novo a inocência e não porque tem adolescente grávida obrigar as crianças a saberem sobre sexo, se me entende? Se náo daqui a pouco a gente vai ter que falar sobre sexo com crianças de 9 anos e depois de 8 anos e ai a onde a gente vai parar? Se me entende? (Terra, 37 anos)

Depois dos quinze, antes disso é muito cedo demais. (Júpiter, 37 anos)

Dez anos, porque essa meninada de hoje está muito assanhada, eu já vi menina dessa idade grávida, eu acho horrivel, mas fazer o que, o mundo está assim hoje né! (Mercúrio, 42 anos)

Dentre os pais entrevistados, alguns acreditam que dez anos é a idade preferencial para início da educação sexual, e justificam essa opiniáo com o estilo de vida contemporâneo e a precocidade da geração atual enquanto que alguns pais referem que onze anos seria a idade ideal para iniciar os conhecimentos educacionais sobre sexualidade. Outros acreditam que catorze anos seja a idade propícia; ainda, alguns pais participantes opinaram que a melhor idade seria a partir dos quinze anos, pois, para eles, antes desse período é cedo demais; essa opinião se torna contraditória pelo fato de os entrevistados possuírem filhas em gestação precoce com a mesma idade, e até mesmo em segunda gestaçáo.

\section{Impactos da gestação precoce}

$\mathrm{Na}$ análise dessa categoria, constatou-se que os participantes não aceitaram a gestação quando receberam a notícia, situação que gerou conflitos variados nas famílias. Porém, com o passar do tempo, acabaram por aceitar a nova situação. Por outro lado, alguns dos participantes admitiram a gestação, uns de forma resiliente, outros relatando felicidade ao descobrir a gravidez da filha.

Quanto ao recebimento da notícia, os pais descreveram reaçóes diversas, com misto de não aceitação, revolta e aceitação, como se nota nas falas:

Foi um susto, eu chorei, gritei, me descabelei, mas náo teve jeito, o erro já estava feito, tive que aceitar, mas fiquei muito tempo brava com ela. (Mercúrio, 42 anos)

Eu quase fiquei louca, quase enfartei, não esperava, foi uma decepçáo muito grande, eu confiava nela, nunca proibi de sair, confiando que ela me respeitaria, mas deu no que deu; agora está tudo bem, mas foi muito difícil aceitar. (Terra, 37 anos)

Eu nem sei sabe, eu não briguei, conversei, por que não tinha o que fazer, eu ia bater nela? Ia botar ela pra fora de casa? Eu não podia fazer nada, a irmã dela já está no terceiro filho; está tudo bem a gente sempre dá um jeito, eu até estou feliz. (Júpiter, 37 anos)

A experiência de ter uma filha adolescente grávida gera sentimentos ambíguos nos familiares, como medo, tristeza, dor, desilusão, julgamento como ato errôneo, alegria, conformismo e expectativas de superação com apoio familiar ${ }^{20}$. Geralmente ao descobrir a gravidez, a adolescente recorre primeiro à mãe, pois a comunicação pode ser melhor estabelecida com essa figura ${ }^{20}$. E a gestação tende a ser melhor aceita pela família quando o vínculo entre o casal de futuros pais já está consolidado e existem planos de casamento ${ }^{21}$.

Nas mudanças trazidas pela gestação precoce da filha, as respostas se mostraram variadas:

A gravidez dela trouxe mudança pro bem e pro mal, deu medo por ela ser muito nova, catorze anos, a gente tem medo de dar algum problema. (Netuno, quarenta anos)

Trouxe, meu filho foi embora de casa, foi morar com a avó, a casa é muito pequena, náo teria como caber ela com o bebê então ele saiu de casa; as coisas estão caras, graças a Deus a gente ganhou bastante roupa mas fraldas e comida está muito caro, apertou demais o nosso orçamento e a gente teve que adiar outros planos. (Terra, 37 anos)

Totalmente, na rotina, financeira, psicológica, em tudo, mudou tudinho mesmo, tem seus dias bons e dias ruins, mas a gente vai levando, a gente teve que se adaptar nessa nova vida, porque mudou tudo mesmo. (Marte, 35 anos)

Observou-se nas respostas o aparecimento de diversos fatores que se alteraram com a gestação, como os aspectos financeiro e psicológico. Entretanto, os mais citados são as mudanças na rotina, os conflitos e a situação psicológica da família. O lado financeiro, mesmo nas famílias que apresentavam pior situação de renda, aparentou ser de última importância.

As reaçóes da família diante da adolescente grávida tendem a ser paradoxais, dada a sobreposição dos sentimentos de aceitação do inevitável, revolta e abandono, podendo esses sentimentos se transformar ou não em apoio $^{18,22}$. O suporte familiar na gestação adolescente auxilia na amenização dos efeitos negativos que esse evento pode trazer, pois a família representa um alicerce para amparo emocional e financeiro, assim 
como para cuidados com a criança e restabelecimento de planos futuros ${ }^{20}$.

\section{Posição quanto à intervenção governamental na educação sexual adolescente}

Nessa temática foram abordadas a aceitação e a resistência dos pais diante da intervenção governamental na educação sexual dos adolescentes. Obtiveram-se como respostas as afirmaçóes:

O governo pode educar junto com os pais, pode tentar né, porque hoje já está tudo explícito mesmo, eles têm celular, computador, a gente nem sabe o que eles tão vendo, mas a gente sabe que eles veem essas coisas aí. (Netuno, 40 anos)

Dos dois, do governo e dos pais, mas, mais dos pais, se não educar desde cedo náo adianta o governo intervir na adolescência. (Terra, 37 anos)

A prioridade é dos pais, o governo tem que ter limite, não pode passar da autoridade do pai e da máe; en que tenho que decidir o que é melhor pros meus filhos. (Marte, 35 anos)

Constatou-se que os pais participantes acreditam que o governo deve interferir na educaçáo sexual dos adolescentes. Alguns opinaram negativamente; outros não souberam opinar de forma decisiva sobre o assunto, e a maioria avaliou que a educação sexual deve ser realizada pelos pais e pelo governo, sendo que a primazia deve ser dos primeiros, tanto para a idade inicial quanto para os níveis desse conhecimento.

A educação sexual dos adolescentes pode contribuir para reduzir problemas na vida social e pessoal. Por isso, é de grande importância o esforço coletivo de pais, profissionais de saúde e educadores no estabelecimento de ambiente favorável à aprendizagem de métodos de prevenção de gravidez precoce e das DST, contribuindo também para o desenvolvimento da autonomia dos adolescentes e oferecendo-lhes conhecimentos para que possam decidir com a devida consciência e responsabilidade o melhor momento de engravidar, de modo que esse seja sempre um período de alegria, felicidade e crescimento pessoal para todos os envolvidos ${ }^{13,23}$.

\section{Conclusão}

Este trabalho identificou a percepção dos pais de adolescentes em gestação precoce quanto à educação sexual preventiva exercida atualmente pelo Ministério da
Saúde em parceria com o Ministério da Educação nas escolas e Unidades Básicas de Saúde (UBS).

Destacaram-se alguns aspectos de maior relevância, como a noçáo que os pais têm de si mesmos, mostrando ora ideias incoerentes com a realidade da família e da sociedade atual, ora concepçóes deveras realistas.

Confirmou-se que o surgimento de uma gestação precoce modifica, de forma geral, a vida de todo o núcleo familiar. Pode-se observar a dificuldade no relacionamento franco entre pais e filhos no que tange ao diálogo, às opinióes e à convivência. Alguns pais se mostraram contraditórios quanto à idade das filhas para iniciação dos conhecimentos de educação sexual: mesmo tendo uma filha gestante se colocaram contra essa educação num período pré-adolescente/adolescente.

Quanto à intervenção governamental, a maioria dos entrevistados considera que a educação sexual deve ser trabalhada em conjunto, pais e governo, porém não aceita que a iniciativa seja tomada por órgáos governamentais, de modo que a decisão inicial deve partir do pai e/ ou da mãe. Entretanto, analisando as entrevistas, se percebeu através da participação das filhas que o aconselhamento e a educação sexual intrafamiliar não condiz plenamente com os relatos maternos e paternos. Nesse caso, pareceu ser realmente uma questáo de pátrio poder, o direito decisório no que diz respeito à vida dos filhos.

Em suma, a temática abordada mostra-se difícil, de ampla complexidade e multicausal, tornando sua resolubilidade algo aparentemente utópico. Somente o trabalho integrado, interdisciplinar, intersetorial, que envolva pais, filhos, famílias, comunidades, profissionais de saúde e educadores, pode ao menos amenizar essa problemática social que é a gestação precoce.

Nessa perspectiva, se faz necessária a realização de mais açóes, como reunióes, grupos de apoio e estratégias de agregação voltadas para o público adolescente e para seus pais, vistas as dificuldades enfrentadas pelas famílias em lidar com tema tão controverso. Há também a necessidade de mais estudos que abordem o assunto, para subsidiar a realização dessas ações.

\section{Referências}

1. Azevedo WF, Diniz MB, Fonseca ESVB, Azevedo LMR, Evangelista CB. Complicaçóes da gravidez na adolescência: revisão sistemática da literatura. Einstein. 2015;13(4):618-26.

2. Instituto Brasileiro de Geografia e Estatística. Indicadores sociodemográficos e de saúde no Brasil. Rio de Janeiro: IBGE; 2009.

3. Brasil. Ministério da Saúde. Departamento de Informática do SUS. Sistema de informaçôes de nascidos vivos 
[Internet]. [atualizado em 2014; citado em 2017 jan 25]. Disponível em: https://goo.gl/ChZ5vD

4. Brasil. Ministério da Saúde. Secretaria de Atenção em Saúde. Departamento de Açóes Programáticas Estratégicas. Diretrizes nacionais para a atenção integral à saúde de adolescentes e jovens na promoção, proteçáo e recuperaçáo da saúde. Brasília, DF: Ministério da Saúde; 2010.

5. Brasil. Lei no 8.069, de 13 de julho de 1990. Dispóe sobre o Estatuto da Criança e do Adolescente e dá outras providências [Internet]. Diário Oficial da União. Brasília, DF; 13 jul 1990 [citado em 2017 out 5]. Disponível em: https://goo.gl/UdwKV

6. Brasil. Ministério da saúde. Secretaria de Atenção à Saúde. Departamento de Açôes Programáticas Estratégicas. Política nacional de atenção integral à saúde de adolescentes em conflito com a lei: normas e reflexóes. Brasília, DF: Ministério da Saúde; 2012. (Série B. Textos Básicos de Saúde)

7. Brasil. Ministério da Saúde. Saúde e prevenção nas escolas: guia para a formação de profissionais de saúde e de educação. Brasília, DF: Ministério da Saúde; 2007.

8. Instituto Brasileiro de Geografia e Estatística [Internet]. Rio de Janeiro: Instituto Brasileiro de Geografia e Estatística [atualizado em 2010; citado em 2015 dez 14]. Disponível em: https://goo.gl/ssG3SY

9. Brasil. Ministério da Saúde. Departamento de Informática do SUS [Internet]. Brasil; [atualizado 2013; citado 2015 dez 14]. Disponível em: https://goo.gl/TV3FiJ

10. Gomes R. A análise de dados em pesquisa qualitativa. In: Minayo, MCS. Pesquisa social: teoria, métodos e criatividade. $21^{\text {a }}$ ed. Rio de Janeiro: Vozes; 2002. p. 67-79.

11. Ruzany MH. Atenção à saúde do adolescente: mudança de paradigma. In: Brasil. Ministério da Saúde. Secretaria de Atenção à Saúde. Departamento de Açóes Programáticas Estratégicas. Saúde do adolescente: competências e habilidades. Brasília, DF: Ministério da Saúde; 2008. p. 21-25. (Série B. Textos Básicos de Saúde)

12. Moreira TMM, Viana DS, Queiroz MVO, Jorge MSB. Conflitos vivenciados pelas adolescentes com a descoberta da gravidez. Rev Esc Enferm USP. 2008;4(2):312-20.
13. Souza TA, Brito MEM, Frota AC, Nunes JM. Gravidez na adolescência: percepçóes, comportamentos e experiências de familiares. Rev Rene. 2012;13(4):794-804.

14. Galante AC, Aranha JA, Beraldo L, Pelá NTR. A vinheta como estratégia de coleta de dados de pesquisa em enfermagem. Rev Latinoam Enfermagem. 2003;11(3):357-63.

15. Fernandes AO, Santos Júnior HPO, Gualda DMR. Gravidez na adolescência: percepçóes das mães de gestantes jovens. Acta Paul Enferm. 2012;25(1):55-60.

16. Monteiro CFS, Costa NSS, Nascimento PSV, Aguiar YA. A violência intra-familiar contra adolescentes grávidas. Rev Bras Enferm. 2007;60(4):373-76.

17. Dias ACG, Gomes WB. Conversas sobre sexualidade na família e gravidez na adolescência: a percepção dos pais. Estudos de Psicologia. 1999;4(1):79-106.

18. Pariz J. Mengarda CF, Frizzo GB. A atenção e o cuidado à gravidez na adolescência nos âmbitos familiar, político e na sociedade: uma revisão de literatura. Saúde Soc. 2012;21(3):623-36.

19. Witter GP, Guimarães EA. Percepções de adolescentes grávidas em relação a seus familiares e parceiros. Psicol Ciênc Prof. 2008;28(3):548-57.

20. Araújo JA, Halboth NV, Araújo A. Humanização e integralidade na atenção à família: a percepção de mães sobre a gravidez de suas filhas adolescentes. Mundo Saúde. 2012;36(3)475-81.

21. Levandowski DC, Barth B, Munhós AAR, Rödde AC, Wendland J. Apoio familiar e gestação na adolescência: um estudo qualitativo com adolescentes do Vale dos Sinos/BR. Rev Interam Psicol. 2012;46(2):297-306.

22. Lima CTB, Feliciano KVO, Carvalho MFS, Souza APP, Menabó JBC, Ramos LS et al. Percepçôes e práticas de adolescentes grávidas e de familiares em relação à gestação. Rev Bras Saúde Matern Infant. 2004;4(1):71-83

23. Carneiro RF, Silva NC, Alves TA, Albuquerque DO, Brito DC, Oliveira LL. Educação sexual na adolescência: uma abordagem no contexto escolar. Sanare. 2015;14(1):104-8.

\section{Como citar este artigo:}

Villas Boas JBR, Gomes MFP, Reticena KO, Capellini VK, Fracolli LA. Percepção dos pais de gestantes adolescentes sobre a educação sexual. Rev. Aten. Saúde. 2017;15(53):37-43. 